\title{
DOSIMETRIA ESPORULAR: Bacillus subtilis TKJ6312 COMO BIOSSENSOR DE RADIAÇÃO SOLAR BIOLOGICAMENTE ATIVA
}

\author{
Marcelo Barcellos da Rosa*, Pabulo Henrique Rampelotto e Nelson Jorge Schuch \\ Laboratório de Exobiologia e Biosfera, Centro Regional Sul de Pesquisas Espaciais, Instituto Nacional de Pesquisas Espaciais, \\ CP 5021, 97110-970 Santa Maria - RS, Brasil \\ André Passaglia Schuch \\ Instituto de Ciências Biomédicas, Universidade de São Paulo, 05508-900 São Paulo - SP, Brasil \\ Nobuo Munakata \\ Faculty of Science, Rikkyo University, 171-8501 Tokyo, Japan
}

Recebido em 30/10/07; aceito em 28/8/08; publicado na web em 26/1/09

\begin{abstract}
SPORE DOSIMETRY: Bacillus subtilis TKJ6312 AS BIOSENSOR OF BIOLOGICALLY EFFECTIVE SOLAR RADIATION. Since 2000, spore dosimetry and spectral photometry have been performed in parallel at the Southern Space Observatory, São Martinho da Serra (Southern Brazil). A comparative study involving data from Punta Arenas - Chile (53.2 $\left.{ }^{\circ} \mathrm{S}\right)$, São Martinho da Serra (29.5 $\mathrm{S})$, Padang - Indonesia $\left(0.9^{\circ} \mathrm{S}\right)$, Brussels - Belgium $\left(50.9^{\circ} \mathrm{N}\right)$ and Kiyotake - Japan $\left(31.9^{\circ} \mathrm{N}\right)$ from 2000 to 2006 is presented. The Spore Inactivation Doses presented the higher values in summer ( $973 \pm 73$ for Punta Arenas and 4,369 \pm 202 for São Martinho da Serra, as well 1,402 \pm 170 and 3,400 \pm 1,674 for Brussels and Kiyotake, respectively). The simplicity, robustness and high resistance of bacterial spores makes the biosensor an potential biological tool for UV-B monitoring.
\end{abstract}

Keywords: spore dosimetry; biosensor; UV-B radiation.

\section{INTRODUÇÃO}

A radiação solar é essencial para a vida na superfície da Terra, mas paradoxalmente é também um fator de estresse ambiental para os organismos vivos. Trabalhos têm mostrado que desde a década de 70 a concentração de ozônio estratosférico tem decrescido em média de $0,5 \%$ ao ano para quase todas as latitudes nas regiões extra-tropicais, devido a emissões antropogênicas de derivados de clorofluorcarbonos. Deste então, a média global de incidência de radiação UV-B (280- 320 $\mathrm{nm}$ ) tem aumentado em torno de $5 \% .{ }^{1} \mathrm{O}$ ácido desoxirribonucléico (DNA), ou seja, o material genético das células é o principal alvo da radiação UV solar. ${ }^{2}$ Portanto, danos causados em organismos vivos devido à exposição solar, incluindo riscos à saúde humana, a ecossistemas terrestres e aquáticos têm sido uma preocupação global. ${ }^{3,4}$ Conseqüentemente, o monitoramento da radiação UV solar tem sido realizado mundialmente.

Esse monitoramento requer instrumentos de coleta de dados de alta sensibilidade, para que se possam dimensionar efetivamente os riscos causados pela radiação UV solar à saúde humana. Atualmente, um método comum para se ter acesso ao potencial dano biológico causado pela radiação solar é o cálculo da dose biologicamente ativa da radiação solar, que é obtida através da transformação de dados da radiação solar incidente com algum espectro de ação biológica de interesse, através do uso de espectrofotômetros. Um porém é que espectrofotômetros são aparelhos normalmente de grande porte, de alto custo operacional e requerem calibrações onerosas, uma vez que necessitam de jogos de lâmpadas e filtros especiais, além de necessitarem de um controle de tensão bastante refinado.

No caso de dosímetros comercialmente disponíveis, que medem o efeito biológico da radiação, têm sido construídos com sensibilidade espectral próxima ao espectro de ação do eritema, definido pela Comissão Internacional de Radiação. ${ }^{5}$ Entretanto, utilizando

\footnotetext{
*e-mail: marcelo.rosa@unipampa.edu.br
}

estes instrumentos de banda larga, os quais fornecem a irradiância integral para toda a faixa espectral que medem para detectar tendências de longo tempo da radiação UV-B, dados controversos têm sido observados. ${ }^{6}$ Para complementar tais dosímetros físicos, diversos biossensores têm sido desenvolvidos, utilizando a vitamina $\mathrm{D}$, uracil, DNA, bacteriófagos, esporos de bactérias, entre outros..$^{7-11}$ Para aplicações em medidas de campo, os dosímetros biológicos devem ser robustos, ou seja, fisiologicamente estáveis por longo período de tempo, de fácil manuseio, fotossensíveis, seguros, de baixo custo e o efeito biológico avaliado deve ser afetado somente pela radiação e não por fatores ambientais e climáticos. ${ }^{12}$

Entre os métodos biológicos citados e propostos na literatura, o uso de biossensor baseado na inativação de esporos de Bacillus subtilis apresenta várias propriedades adequadas para sua utilização como dosímetro solar biológico, incluindo sua simplicidade, facilidade de manuseio e transporte para o local de teste, possibilidade de armazenamento prolongado estável antes e depois da exposição, bem como uma reprodutibilidade da resposta de inativação.

Tentativas de aplicar este dosímetro sob várias condições têm sido bastante estudadas na última década e comparações com dosímetros físicos têm sido realizadas geralmente com a taxa de dose sendo determinada em minutos. ${ }^{13,14}$ Entretanto, para aplicação de longo período, sob diversas condições climáticas, alguns problemas surgem e serão discutidos posteriormente.

Neste trabalho são apresentados os resultados de monitoramentos mensais contínuos da radiação biologicamente ativa usando dosimetria esporular no sul do Brasil, bem como comparações com outras localidades espalhadas em diversas latitudes e continentes.

\section{PARTE EXPERIMENTAL}

Medidas físicas de radiação podem ser realizadas com espectrofotômetros Brewer capazes de medir além da radiação na faixa de UV-B e UV-A, $\mathrm{O}_{3}, \mathrm{NO}_{2}, \mathrm{SO}_{2}$ e espalhamento rayleigh. Os modelos MKII 
056 (2000-2002) e MKIII 167 (2002-atual) medem a radiação UV na faixa espectral de 286,5 a 363,0 nm, com uma resolução de $0,5 \mathrm{~nm}$. Neste estudo, as medidas de radiação UV-B obtidas pelos Brewer's foram ponderadas com o espectro de ação dos esporos utilizando o software UV-Brewer versão 2.1 e seguindo uma calibração quinzenal utilizando-se lâmpadas padrões externas.

As medidas de radiação biologicamente ativa, empregando a dosimetria esporular, consistem na utilização de esporos de Bacillus subtilis TKJ6312. Devido à deficiência, ou modificação de ambos mecanismos de reparo do DNA esporular, NER e liase SP, estes se tornam sensíveis à radiação solar UV, o que possibilita a sua utilização como um dosímetro solar biológico para monitorar a fração da radiação solar UV que é biologicamente ativa. O dosímetro de esporos tem sido preparado no Laboratório de Ciência da Vida da Faculdade de Ciências da Universidade Rikkyo, Tóquio, Japão, onde os esporos da cepa mutante de Bacillus subtilis TKJ6312 são misturados com $0,6 \%(\mathrm{~m} / \mathrm{v})$ de agarose. ${ }^{15}$ Quatro alíquotas de $5 \mu \mathrm{L}$ dessa suspensão, cada uma contendo aproximadamente $10^{6}$ esporos são adicionadas sobre um filtro de membrana e dispostos em slides. Em seguida, uma amostra é coberta com cartão (controle). Por último, as três amostras que serão expostas à radiação solar local são cobertas uma lâmina de polietileno azul de 0,04 mm (modelo BPS04) de espessura e protegidas em outra lâmina de polietileno azul de $0,07 \mathrm{~mm}$ (modelo BPS07) de espessura. As lâminas de polietileno azul BPS04 e BPS07 são adequadas para esse uso, pois suas transmitâncias são uniformes na faixa espectral de 254 a $365 \mathrm{~nm} .{ }^{16}$ As amostras, após exposição, são então armazenadas no escuro até revelação. Após exposição, cada membrana é recortada e disposta em tubo de ensaio. Um volume de $1,0 \mathrm{~mL}$ de água é adicionado e aquecido a $75^{\circ} \mathrm{C}$ por $15 \mathrm{~min}$ visando a liberação dos esporos para solução. Na sequiência, uma alíquota da suspensão é colocada em um meio de cultura agar mínimo suplementado com ácido casamínico e as colônias contadas após uma incubação de $24 \mathrm{~h}$ a $37^{\circ} \mathrm{C}$. A média dos esporos das três amostras expostas $\left(\mathrm{N}_{\mathrm{e}}\right)$ é então dividida pelos esporos da amostra controle, não exposta $\left(\mathrm{N}_{\mathrm{c}}\right)$, para se obter a fração de sobrevivência $\left(\mathrm{N}_{\mathrm{e}} / \mathrm{N}_{\mathrm{c}}\right)$ dos esporos em função da quantidade de radiação incidente biologicamente ativa, ou capaz de inativar os esporos. A dose de inativação esporular, SID (Spore Inactivation Doses), é obtida do valor absoluto do logaritmo natural da fração de sobrevivência da Equação 1

$$
\mathrm{SID}=-\ln \left[\mathrm{N}_{\mathrm{e}} / \mathrm{N}_{\mathrm{c}}\right]
$$

O espectro de ação dos esporos é determinado através de experimentos laboratoriais que analisam o efeito biológico para cada comprimento de onda da faixa espectral desejada. Utilizando-se esporos suspensos em agarose e adicionados em filtros de membrana, o espectro de ação de inativação dos esporos é obtido usando um espectrômetro modificado para este fim, Okazaki Large Spectrograph, que abrange os comprimentos de onda de 254 a $400 \mathrm{~nm} .{ }^{17}$ Esse espectro de ação é então utilizado para as comparações com detectores físicos através de cálculos de eficiência como formulado por Setlow et al. ${ }^{18}$

Portanto, o monitoramento mensal da radiação biologicamente ativa usando dosimetria esporular vem sendo realizado desde 2000 no Observatório Espacial do Sul $\left(29.4^{\circ} \mathrm{S}, 53.8^{\circ} \mathrm{O}\right.$ - OES/INPE) em São Martinho da Serra, RS, e comparado com outras localidades distribuídas em diversas latitudes e em diferentes hemisférios, como Punta Arenas - Chile $\left[53.2^{\circ} \mathrm{S}\right.$ ], Padang - Indonésia [0.9 $\left.{ }^{\circ} \mathrm{S}\right]$, Kiyotake - Japão $\left[31.9^{\circ} \mathrm{N}\right]$ e Bruxelas - Bélgica $\left[50.9^{\circ} \mathrm{N}\right]$. Além disso, para os dados do OES, os dados do dosímetro biológico têm sido comparados com dados de integrais mensais de radiação UV-B e de SID calculadas espectrofotometricamente.

\section{RESULTADOS E DISCUSSÃO}

Exposições mensais do dosímetro esporular vêm sendo continuamente realizadas desde março de 2000, com o objetivo de obter séries temporais e analisar a variação sazonal e as amplitudes intersazonais da radiação ultravioleta solar biologicamente ativa para a latitude do OES $\left(29,4^{\circ} \mathrm{S}\right)$.

A série temporal (Figura 1) mostra uma razão praticamente constante entre as amplitudes de radiação medida fisicamente $\left(U \mathrm{U}_{\text {Brewer }}\right.$ ) e SID na ordem de UV-B Brewer $\approx 200$ SID. Essa razão, relativamente contínua, alta e para toda a variação sazonal ratifica a potencialidade dos esporos, pois, além de variar numa faixa linear bastante ampla, as integrais mensais de radiação são visivelmente correlacionáveis (Figura 2) com os valores de SID. Para a aplicação a campo e de rotina confiável, os esporos devem preencher os mesmos critérios radiométricos de qualquer outro dosímetro, confirmados experimentalmente neste trabalho. Portanto, torna-se importante uma intercomparação entre dosímetros biológicos com físicos para se verificar a existência de uma relação analítica entre os esporos e as medidas físicas de radiação. A principal vantagem de um dosímetro biológico reside em sua medida direta da radiação que é biologicamente ativa, ou seja, a que causa danos a organismos sem a necessidade de complexos hardwares e softwares requeridos pelos dosímetros físicos. Outro aspecto importante é o fato de não existir na literatura uma validação analítica consistente, ou um estudo mais criterioso envolvendo figuras de mérito para medidas que envolvem

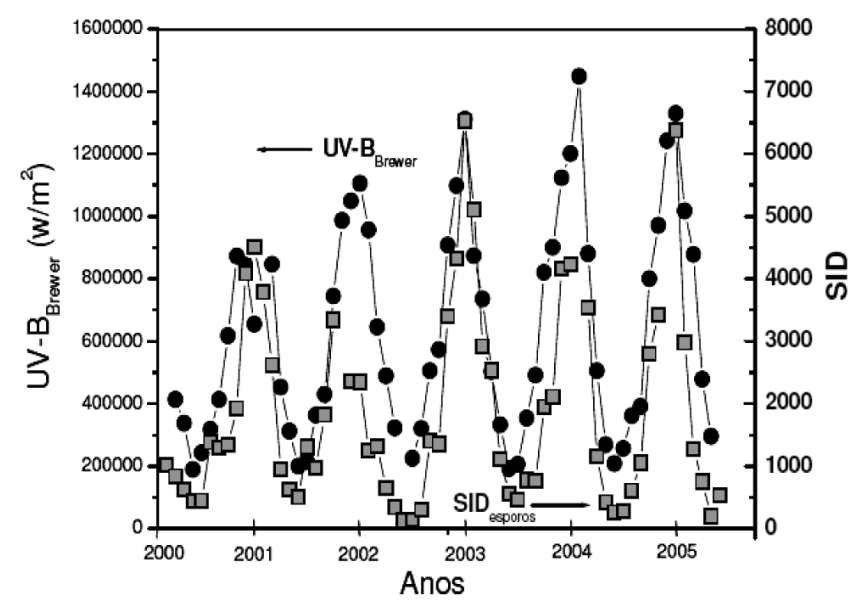

Figura 1. Série temporal das medidas de UV-B obtidas pelo Brewer (•) e da dose de inativação esporular (ם) para o período de 2000 - 2006

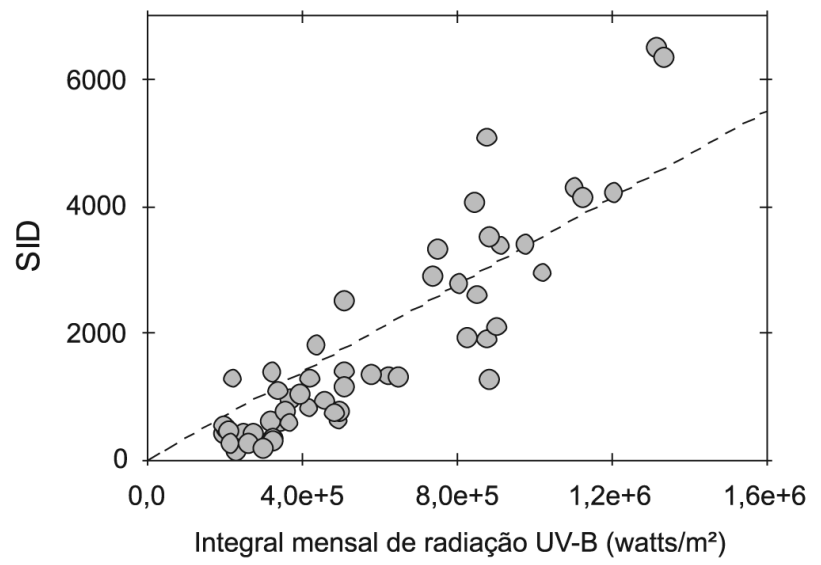

Figura 2. Correlação entre as medidas das integrais mensais de radiação $U V$-B (Brewer) e das exposições mensais envolvendo os esporos (SID) 
longas séries temporais de medidas de radiação. Assim, torna-se difícil analisar os dados para escalas temporais longas apenas com base em calibrações esporádicas, uma vez que equipamentos, como o espectrofômetro Brewer, exigem para tanto uma combinação de dias sem nuvens para a realização das mesmas. Teoricamente seria recomendada uma calibração quinzenal para todo e qualquer modelo de Brewer, porém a combinação temporal (quinzenal) e dia de céu limpo, ou sem nuvens, pode ser um limitante prático.

Através de uma regressão linear um elevado coeficiente de correlação $(\mathrm{r} \sim 0,94, \mathrm{p}<0,0001)$ entre as medidas físicas e biológicas é obtida (Figura 2).

Para uma aplicação de rotina confiável, o dosímetro de esporos deve preencher um conjunto de critérios estabelecidos pelo projeto BIODOS da Comissão Européia, que se preocupa em desenvolver sistemas dosimétricos biológicos para monitorar o impacto da radiação UV ambiental na saúde humana e biosfera. ${ }^{19}$ Um dos critérios mais importantes para a validação de um dosímetro biológico, como destacado anteriormente, é a relevância do processo fotoquímico/ fotobiológico do dosímetro em relação a diferentes efeitos biológicos. Apesar do fato de que muitos sistemas biológicos diferem em seus espectros de ação para o foto-dano causado pela radiação, uma vez que suas fisiologias são diferentes, todos possuem em comum o mais importante constituinte para dano induzido por UV, o DNA.

$\mathrm{Na}$ grande maioria de diferentes efeitos biológicos finais, o processo chave é o dano causado ao DNA pela radiação UV. Como conseqüência, muitos sistemas biológicos possuem um espectro de ação similar na região UV-B, a região espectral no qual o DNA apresenta seu maior coeficiente de extinção relativo. ${ }^{19}$ Portanto, a taxa de inativação esporular, conseqüente do dano ao DNA dos esporos, induzida pela radiação, pode vir a ser usada como uma medida da radiação biologicamente ativa para outros sistemas biológicos.

Para se obter dados reprodutíveis e confiáveis, o procedimento deve ser padronizado e o sistema biológico deve ser bem definido, por exemplo, por cepas bem definidas geneticamente. Esse pré-requisito indica também a necessidade de se obter séries longas de dados, como é o caso deste trabalho, uma vez que se procura uma relação entre uma resposta física ponderada por um espectro e uma resposta fisiológica de dano ao DNA dos esporos. A operação do dosímetro de esporos tem demonstrado ser, a priori, independente de condições ambientais e estável com o tempo. Exigências rígidas têm sido estabelecidas e cumpridas na utilização dos esporos em termos das propriedades radiométricas, as quais incluem o espectro de ação definido, a faixa linear de resposta bastante ampla, apresenta uma resposta absoluta e relativa, o potencial de interações policromáticas é definido pelo espectro de ação e sua dependência de fatores ambientais é praticamente inexistente. ${ }^{19}$ Portanto, todos esses aspectos vêm sendo estudados em detalhe ao longo desta proposta de utilização do biossensor. ${ }^{20}$

A sazonalidade da radiação ultravioleta biologicamente ativa obtida no OES, considerados os valores médios de SID observado (pelos esporos) e o SID calculado (pelo Brewer), para o período de 2000 - 2006, é mostrada na Figura 3.

Uma vez comparados os valores medidos ( SID $_{\text {observado }}$ ) e calculados pelo Brewer ( SID $_{\text {calculado }}$ ), observa-se que os dados são estatisticamente iguais. Como esperado, a variação temporal da radiação ultravioleta solar biologicamente ativa medida como SID mensal apresenta um caráter marcadamente sazonal associada ao ciclo anual do ângulo solar de zênite. Uma notável similaridade existe entre os valores de SID observado e calculado, sinalizando a aplicabilidade dos esporos na determinação de doses biologicamente ativas obtidas por espectrofotômetros Brewer, que confirma o sistema biológico como biossensor para o monitoramento das mudanças sazonais na radiação solar UV na superfície terrestre.

Devido às propriedades radiométricas do biossensor, a possi-

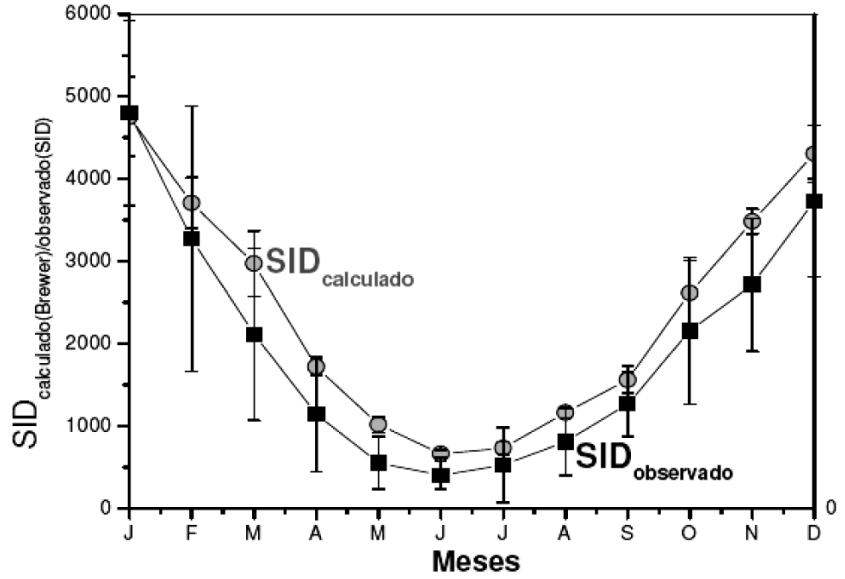

Figura 3. Relação entre os valores de SID calculados pelo Brewer (○) com base no espectro de ação e os valores de SID obtidos pelos esporos ( $\mathbf{\square})$

bilidade de se quantificar a radiação UV solar em uma ordem de magnitude que pode ser comparada a outras medidas obtidas espectrofotometricamente e a possibilidade de conversão para outras unidades de importância médica/fotobiológica torna-se também viável. ${ }^{21-23}$

Em relação aos dados comparativos entre as diferentes estações espalhadas em diferentes continentes, uma variação da radiação ultravioleta solar biologicamente para baixas, médias e altas latitudes, é apresentada na Figura 4.

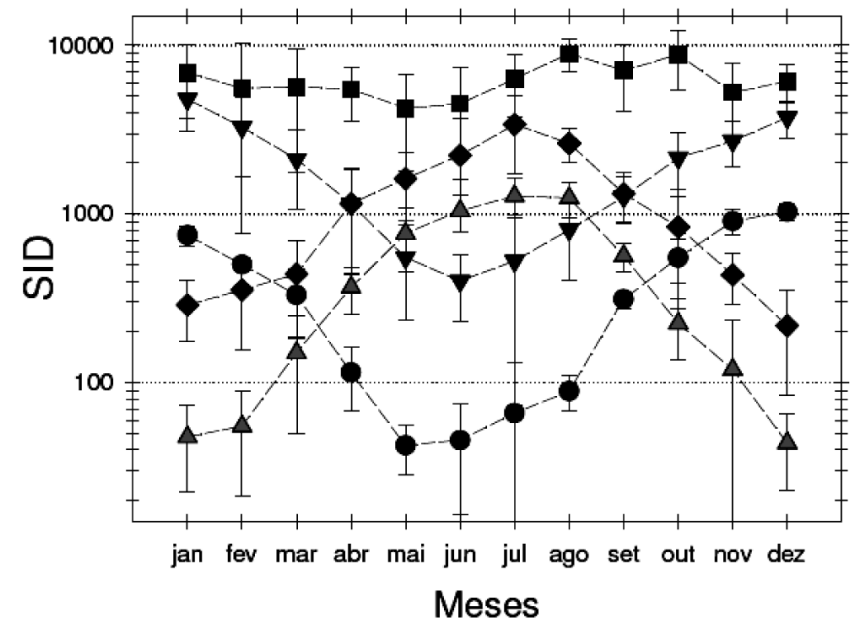

Figura 4. Comparação entre os valores de SID para diferentes latitudes e

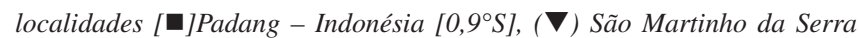
$\left[29,4^{\circ} \mathrm{S}\right],[\diamond]$ Kiyotake - Japão $\left[31,9^{\circ} \mathrm{N}\right],[\Delta]$ Bruxelas - Bélgica $\left[50,9^{\circ} \mathrm{N}\right]$ e [•]Punta Arenas - Chile [53,2 ${ }^{\circ}$ S]) para o período de 2000 até 2006

Variações sazonais foram observadas nas estações não equatoriais. Os máximos valores de SID foram obtidos para o verão (973 \pm 73 para Punta Arenas e $4.369 \pm 202$ para São Martinho da Serra, bem como $1402 \pm 170$ e $3400 \pm 1674$ para Bruxelas e Kiyotake, respectivamente) e os menores para o inverno (33 \pm 8, $332 \pm 149,44 \pm$ 21 e $163 \pm 63$ para Punta Arenas, São Martinho da Serra, Bruxelas e Kiyotake, respectivamente). As razões sazonais entre $\mathrm{SID}_{\mathrm{MAX}} / \mathrm{SID}_{\mathrm{MIN}}$ para cada localidade foram obtidas para Punta Arenas $\left(\mathrm{SID}_{\mathrm{MAX}} / \mathrm{SID}_{\mathrm{MIN}}\right.$ $=24)$ e Bruxelas $\left(\operatorname{SID}_{\text {MAX }} /\right.$ SID $\left._{\text {MIN }}=29\right)$, estações que apresentam maiores latitudes e, conseqüentemente, as menores irradiâncias. Em Padang foram observados os maiores valores de SID, acima de 6.000 , não sendo este valor observado para outras estações. A razão sazonal ( $\mathrm{SID}_{\mathrm{MAX}} / \mathrm{SID}_{\mathrm{MIN}}$ ) para Padang foi significativamente menor que aquelas das outras estações $\left(\mathrm{SID}_{\mathrm{MAX}} / \mathrm{SID}_{\mathrm{MIN}}=2\right)$ e quando com- 
parada à $\mathrm{SID}_{\mathrm{MAX}} / \mathrm{SID}_{\mathrm{MIN}}=12$ para São Martinho da Serra e $\mathrm{SID}_{\mathrm{MAX}} /$ $\mathrm{SID}_{\text {MIN }}=15$ para Kiyotake. Além disso, a variação sazonal para uma latitude de $0,9^{\circ} \mathrm{N}$ (Padang - Indonésia), devido à proximidade equatorial, acaba refletindo uma climatologia típica que consiste de duas estações ao longo do ano, seca (de março a setembro) e chuvosa (de outubro a abril).

Como dosímetro biológico, os esporos são o de maior abrangência global, e por ser o mesmo método utilizado em todos os locais, apresenta-se como uma ferramenta adequada para o monitoramento global da radiação solar ultravioleta. ${ }^{24}$ Além disso, como os esporos são altamente resistentes a condições extremas do ambiente, trabalhos recentes têm sugerido o uso do biossensor para estudos fotoquímicos e fotobiológicos em ambiente extraterrestre. ${ }^{25}$

Apesar do dosímetro de esporos apresentar os critérios exigidos pelo BIODOS para aplicação a campo de longo período, alguns aspectos precisam ser ainda melhor elucidados. Estudos recentes têm demonstrado que sob exposição solar, o DNA dos esporos acumula vários danos incluindo dímeros de pirimidina, além de quebras na fita simples e dupla. ${ }^{26}$ Portanto, pela grande diversidade de danos no DNA dos esporos induzidos pela exposição à radiação solar, estes precisam ser reparados por uma ampla variedade de sistemas de reparo de DNA em adição à liase SP e NER. Estas considerações ressaltam a importância de estudos complementares dos mecanismos pelos quais os esporos manifestam suas propriedades de resistência.

Além disso, alguns trabalhos têm mostrado que a radiação UVA, especialmente na banda $320-365 \mathrm{~nm}$, também pode induzir a formação de dímeros da pirimidina. ${ }^{27}$ Dessa forma, a contribuição da radiação UV-A, bem como a influência da radiação difusa, infravermelha e os resultados espectrofotométricos obtidos para longas séries temporais ainda precisam ser revistos. ${ }^{28-30}$

\section{CONCLUSÕES}

Alguns aspectos envolvendo as potencialidades da dosimetria esporular como proposta de biossensor para radiação solar foram apresentados neste trabalho.

A possibilidade de monitoramento da radiação solar por longas séries temporais destaca a importância deste trabalho, uma vez que, até então, o foco dos trabalhos tem sido voltado para a compreensão que envolve a resposta analítica dos esporos frente à radiação solar biologicamente ativa. Além disso, medidas de SID para diferentes latitudes, porém mesmo hemisfério, e para mesmas latitudes e em hemisférios diferentes ratificam a potencial aplicação da dosimetria esporular como proposta de biossensor global de radiação.

$\mathrm{O}$ fato dos esporos serem inertes a diferentes condições ambientais torna-os robustos e adequados também para estudos voltados à temática da exobiologia, que envolve a compreensão do aparecimento da vida em ambientes extraterrestres. Assim, este trabalho indica também a potencialidade de aplicação da dosimetria esporular, tanto em termos de exposição pessoal, quanto no monitoramento local, regional e global de radiação em ambientes com condições ambientais extremas como a de outros planetas de nosso sistema solar.

\section{REFERÊNCIAS}

1. Rozema, J.; Boelen, P.; Blokker, P.; Environ. Pollut. 2005, 137, 428.

2. Cadet, J.; Sage, E.; Douki, T.; Mutat. Res. 2005, 571, 3.

3. Bednarska, K.; Wachowicz, B.; Buczynski, A.; J. Photochem. Photobiol., B 2000, 55, 109
4. Day, T. A.; Neale, P. J.; Annи. Rev. Ecol. Syst. 2002, 33, 371.

5. McKinley, A. F.; Diffey, B. L.; CIE J. 1987, 6, 17.

6. Blumthaler, M.; Ambach, W.; Silbernagl, R.; Staehelin, J.; Photochem. Photobiol. 1994, 60, 657.

7. Galkin, O. N.; Terenetskaya, I. P.; J. Photochem. Photobiol., B 2000, 53, 12.

8. Horvath, R.; Kerekgyarto, T.; Csuks, G.; Gáspár, S.; Illyes, P.; Rontó, G.; Papp, E.; Biosens. Bioelectron. 2001, 16, 17.

9. Regan, J. D.; Carrier, W. L.; Gucinski, H.; Olla, B. L.; Yoshda, H.; Fijimura, R. K.; Wicklund, R. I.; Photochem. Photobiol. 1992, 56, 35.

10. Hegedus, M.; Modos, K.; Rontó, G.; Fekete, A.; Photochem. Photobiol. 2003, 78, 213.

11. Munakata, N.; J. Radiat. Res. 1989, 30, 338.

12. Horneck, G.; Development of biological dosimetry systems for monitoring the impact of solar UV radiation on the biosphere and on human health, BIODOS, Progress Report No.1, 1997.

13. Munakata, N.; Makita, K.; Bolsée, D; Gillotay, D.; Homeck, G.; Adv. Space Res. 2000, 26, 1995.

14. Schuch, A. P.; Guarnieri, R. A.; Rosa, M. B.; Pinheiro, D. K.; Munakata, N.; Schuch, N. J.; Adv. Space Res. 2006, 37, 1784.

15. Munakata, N.; Morohoshi, F.; Hieda, K.; Suzuki, K.; Furusawa, Y.; Shimura, H.; Ito, T.; Photochem. Photobiol. 1996, 63, 74.

16. Munakata, N., Kazadzis, S.; Bais, A. F.; Hieda, K.; Rontó, G.; Rettberg, P.; Horneck, G.; Photochem. Photobiol. 2000, 72, 739.

17. Munakata, N.; Rupert, C. S.; Mutat. Res. 1975, 27, 157.

18. Setlow, R. B.; Proc. Natl. Acad. Sci. U. S. A. 1974, 71, 3363.

19. Horneck, G.; Adv. Space Res. 2000, 12, 1983.

20. Rampellotto, P. H.; Schuch, A. P.; Rosa, M. B.; Schuch, N. J.; Pinheiro, D. K.; Munakata, N.; Revista Brasileira de Toxicologia 2007, 20, 119.

21. Rosa, M. B.; Schuch, N. J.; Rampellotto, P. H.; Lima, A. P.; Schuch, A. P.; Pinheiro, D. K.; Munakata, N.; Resumo do $10^{\text {th }}$ International Congress of the Brazilian Geophysical Society, Rio de Janeiro, Brasil, 2007.

22. Rampellotto, P. H.; Lima, A. P.; Schuch, A. P.; Pinheiro, D. K.; Schuch, N. J.; Munakata, N.; Resumo do First Brasilian Workshop on Astrobiology, Rio de Janeiro, Brasil, 2006.

23. Rampelotto, P. H.; Lima, A. P.; Pinheiro, D. K.; Schuch, N. J.; Munakata, N.; Resumo do $14^{\circ}$ Simpósio Internacional de Iniciação Científica da USP, São Paulo, Brasil, 2006.

24. Munakata, N.; Cornain, S.; Kanoko, M.; Mulyadi, K.; Lestari, S.; Wirohadidjojo, W.; Bolseé, D.; Kazadzis, S.; Meyer-Rochow, V.; Schuch, N.; Casiccia, C.; Kaneko, M.; Liu, C. M.; Jimbow, K.; Saida, T.; Nishigori, C.; Ogata, K.; Nonaka, S.; Hieda, K.; Ichihashi, M.; Photochem. Photobiol. 2006, 82, 689 .

25. Rampellotto, P. H.; Rosa, M. B.; Schuch, A. P.; Schuch, N. J.; Pinheiro, D. K.; Munakata, N.; Astrobiology 2007, 7, 528.

26. Slieman, T. A.; Nicholson, W. L.; Appl. Environ. Microbiol. 2000, 66, 199.

27. Douki, T.; Reynaud-Angelin, A.; Cadet, J.; Sage, E.; Biochemistry 2003, 42, 9221.

28. Hanlin, J. H.; Lombardi, S. J.; Slepecky, R. A.; J. Bacteriology 1985, 163,774 .

29. Lam, K. S.; Savastiouk, V.; Fung, W. Y.; Chan, T. K.; Lamb, K.; J. Geophys. Res. 2007, 112, d15104.

30. Lakkala, K.; Arola, A.; Heikkila, A.; Kaurola, J.; Koskela, T.; Kyro, E.; Lindfors, A.; Meinander, O.; Tanskanen, A.; Grobner, J.; Hulsen, G.; Atmos. Chem. Phys. Discuss. 2008, 8, 141. 